\title{
O CUIDAR EM SITUAÇÃO DE MORTE: ALGUMAS REFLEXÕES
}

\author{
THE CARE IN DEATH SITUATIONS: SOME REFLECTIONS
}

Luciana G. A. de Souza1 ${ }^{1}$ Magali R. Boemer ${ }^{2}$

${ }^{1}$ Psicóloga. Docente da Faculdade de Ciências Humana de Aguaí - SP. ${ }^{2}$ Docente Aposentada. Escola de Enfermagem de Ribeirão Preto - USP.

Correspondência: Rua Júlio de Souza, 220. Jardim Santa Helena -CEP 13806-034 - Mogi Mirim - SP.- Fones: 19) 3862-3505 / $9762-8549$.

E-mail: lugasouza@yahoo.com.br

Souza LGA, Boemer MR. O cuidar em situação de morte: algumas reflexões. Medicina (Ribeirão Preto) 2005;38 (1): 49-54.

Resumo: A percepção das vivências de morte e morrer tem sofrido transformações ao longo da história, passando de uma experiência tranqüila e até mesmo desejada a uma possibilidade impregnada de angústias e que deve ser evitada a todo custo. Neste contexto, os profissionais de saúde têm uma responsabilidade grande em discutir e refletir sobre a questão de modo que possam oferecer um cuidado autêntico e compromissado com o ser humano, em sua plenitude. Este trabalho se propõe a discutir, a partir da perspectiva da fenomenologia de Heidegger, a questão da morte como parte inerente à existência humana, atentando para a necessidade de que se compreendam as relações de cuidado e as formas de relacionamento humano de modo que se possibilite o preparo dos profissionais de saúde para compartilhar com os pacientes de um momento existencial que pode e deve ser vivido com dignidade.

Descritores: Morte. Profissional de Saúde. Relações de Cuidado.

Para iniciar as reflexões deste artigo, faz-se relevante uma breve apresentação para que o leitor possa se inteirar do contexto de onde proponho suscitar algumas facetas do pensar o profissional de saúde frente à morte do adulto. Realizei minha formação acadêmica em psicologia, tendo, desde os anos iniciais, um significativo interesse pelas questões existenciais. Em meus primeiros contatos com a pesquisa científica, tive a oportunidade de fazer parte do Grupo de Pesquisa "Estudos fenomenológicos sobre a morte e o morrer", durante os anos de 1997 a 2001, grupo este que é coordenado pela Professora Magali Roseira Boemer, quando tive contato com os estudos de diversos autores que tratavam de várias facetas do tema em questão. Também pude conhecer o referencial teórico filosófico da Fenomenologia, que busca estudar o ser-pleno da existência humana e desvelar facetas de fenômenos que se encontram ocultos para uma consciência, no caso a do pesquisador.

Desta vivência, emergiram algumas inquietações que deram origem à minha Monografia de Iniciação Científica e Dissertação de Mestrado ${ }^{1,2}$. O tema que trabalhei mais profundamente em minha trajetória científica foi a questão do cuidado da pessoa com necessidades especiais como uma experiência que implica em interagir com várias mortes, entendidas, em um primeiro momento, como não possibilidades e limitações humanas, provocadas pela deficiência. Para que o cuidado dessas pessoas possa ser realmente significativo há a necessidade de perceber que a pessoa com necessidades especiais tem uma existência diferente da esperada e, assim, também plena de possibilidades e realizações.

Ainda em minha formação profissional tive opor- 
tunidade de estagiar junto ao Grupo de Apoio à Criança com Câncer da FMRP-USP, por um período de um ano e meio, entre 1999 e 2000. Também estagiei no Grupo de Reabilitação de Mulheres Mastectomizadas da EERP-USP, por um ano, em 2001. Tais experiências puderam me aproximar ainda mais do cuidado com o paciente que vivenciou ou vivencia uma doença grave.

Em minha atuação profissional mais recente fui professora de psicologia para o curso de Habilitação Técnico Profissionalizante em Enfermagem, nos anos de 2003 e 2004, na cidade de Mogi Guaçu - SP. Atualmente trabalho clinicamente e sou docente da disciplina de Psicologia na Faculdade de Ciências Humanas de Aguaí - SP, ministrando aulas para os cursos de Pedagogia e Serviço Social e tendo sempre comigo a responsabilidade de abordar questões referentes à compreensão da existência humana como proposta de formação de profissionais compromissados com o ser humano em sua plenitude nas áreas de saúde e educação.

Direcionando-me para o tema que me proponho discutir, é importante ressaltar que, quando se pensa em refletir sobre questões de morte e morrer, é necessário considerar as transformações históricas pelas quais passou a sociedade no que diz respeito às atitudes diante da morte. Da morte vivida com preparo e tranqüilidade na Idade Média, ela passou a um momento de temor e aflição do homem nos dias atuais. A cultura ocidental lhe imprimiu uma intensa angústia que pode ser percebida em situações de aversão e terror frente ao simples imaginar tal possibilidade. Espera-se que a morte ocorra no hospital, quando o indivíduo já atingiu uma idade avançada, devendo acontecer sem sofrimento para a pessoa, de preferência durante o sono ${ }^{3 / 8}$.

Diante disso, os profissionais de saúde são aqueles que têm a incumbência de zelar pelo cuidado da saúde do homem, de modo a postergar, o máximo possível essa vivência tão temida. Frente ao contato muito próximo com situações que revelam a possibilidade humana da morte, esses profissionais se vêem perante a expectativa de que sua função é curar e restabelecer a saúde de todos os que lhes procuram, perdendo de vista que a morte é inerente à condição humana. Há situações em que, a despeito de todo o esforço da equipe de saúde, o paciente morre, e isso passa a ser vivenciado como frustração intensa por parte dos profissionais que sentem que não foram capazes de salvar a vida que lhes foi confiada.
Nos anos 60, Kübler-Ross ${ }^{4}$ já se preocupava com os profissionais de saúde que cuidam de pacientes em situações de morte e morrer, propondo seminários de discussão sobre o tema da morte. A autora deparou-se com reações claramente hostis frente à sua proposta, mas acreditou que a reflexão e discussão do tema poderiam suscitar questões importantes sobre a vivência humana e mais ainda, sobre a natureza do cuidado à pessoa que vivencia sua finitude.

Para Pitta ${ }^{9}$, o trabalho em saúde é vivido com prazer e angústia. Prazer referente à valorização social que esse cuidado tem em nossa cultura ocidental e, por consequiência, os profissionais também são igualmente valorizados por serem pessoas destinadas ao cuidar de quem está sofrendo. Angústia, por sua vez, por trazer ao profissional o inevitável contato com sua impotência frente à morte, o que pode ser fonte de estresse e sofrimento psíquico para esses trabalhadores. Cabe aqui mencionar que, nas últimas décadas, a situação do sistema de saúde brasileiro, tem se deparado com a insuficiência de recursos humanos, baixos salários, precariedade de infra-estrutura, falta de medicamentos, o que vem obrigando os profissionais a trabalharem em situações de grande exigência emocional. Neste contexto, inúmeras questões podem se apresentar como conflituosas para a equipe de saúde como: revelar ou não quando é diagnosticada uma doença grave, possibilidade de envolvimento emocional com o paciente, que tipo de atenção deve ser dada ao doente fora de possibilidades terapêuticas, quando é preciso intervenção psicológica para pacientes em estado grave, entre outras.

Segundo Ayres ${ }^{10}$, quando pensamos em assistência em saúde, relacionamos de imediato o uso de tecnologias para o bem estar físico e mental do ser humano com a seguinte equação: "a ciência produz o conhecimento sobre as doenças, a tecnologia transforma este conhecimento em saberes e instrumentos para a intervenção, os profissionais aplicam esses saberes e produz-se saúde”. Mas, ressalta esse autor, é preciso considerar que este caminho tem trazido grandes questionamentos no que se refere à perda de limites entre o que os profissionais enxergam enquanto necessidade real de intervenção junto ao paciente e o que faz parte de sua ânsia pessoal por encontrar a cura quando ela não é possível.

Precisamos ter claro também que nem tudo que é importante para o bem estar pode ser imediatamente traduzido e operado como conhecimen- 
to técnico. (...) Precisamos estar atentos para o fato de que nunca, quando assistimos 'a saúde de outras pessoas, mesmo estando na condição de profissionais, nossa presença na frente do outro se resume ao papel de simples aplicador de conhecimentos. Somos sempre alguém que, percebamos ou não, está respondendo perguntas do tipo: 'O que é bom pra mim?', 'Como devo ser?', 'Como pode ser a vida?' (Mendes Gonçalves e Schraiber, apud Ayres, 2003-2004) ${ }^{10}$.

Pesados investimentos têm sido aplicados, nas últimas décadas, em tecnologias para intervenções na área da saúde na tentativa de melhorar as condições de vida humana, trazendo a cura e/ou a reabilitação para um número cada vez maior de enfermidades. No entanto, apesar de trazer conforto e bem-estar ao homem moderno, temos percebido que tais inovações também podem estar favorecendo um contato profissional-paciente cada vez mais desumano, desprovido de vínculos.

E atualmente, como nos posicionamos frente a uma proposta semelhante à de Kübler-Ross ${ }^{4}$, na década de 60? Trataríamos com indiferença? Com hostilidade? Com curiosidade? É importante perceber que, em tempos atuais, o tema já não causa tanta aversão e parece que caminhamos para propostas de intervenções em saúde mais direcionadas para questões das reais necessidades do ser humano enquanto passível de morte. Entretanto, ainda temos um longo caminho a percorrer para que a morte, em nossa sociedade, seja respeitada e vivida com dignidade.

Para que se possa pensar mais profundamente sobre o tema, proponho recorrermos à ontologia de Heidegger ${ }^{11,12}$, que foi um filósofo que embasou seu pensar em alguns pressupostos teóricos filosóficos da fenomenologia, que é o referencial teórico que recorro para tecer minhas reflexões. Este autor se preocupa e questiona o significado da palavra "ser" ou "sendo" enquanto fundamento da existência do homem e do mundo à sua volta. Para ele, o "ser" é a maneira como algo se torna manifesto, percebido, compreendido e, finalmente, conhecido pelo ser humano. Ele procura as origens genuínas que possibilitam a tudo se manifestar, o que possibilita as várias maneiras de algo se tornar presente, manifesto, partindo do cotidiano para aproximar-se dos problemas fundamentais e não dos conceitos pré-estabelecidos.

Cabe ainda ressaltar que este autor expressa seu entendimento do "ser" através de palavras amal- gamadas pelo uso de hífens, como "ser-com", "ser-ai", "ser-no-mundo", entre outras, como um idioma próprio. "Heidegger proclama estar retornando, de fato, às origens da linguagem, estar realizando as intenções autênticas do discurso humano" ${ }^{13}$. Assim, este filósofo usa quase sempre palavras simples, mas com significação complexa, que busca traduzir o significado original daquela palavra para que possa ser efetivamente utilizada para explicitar facetas da existência.

É importante atentar para o pressuposto, segundo este referencial, de que o "ser" sempre é um "ser-aî", ou seja, está inserido em um mundo no qual foi lançado e o habita, de forma que não há como conceber um ser isolado, sendo sempre um "ser-nomundo", o que pode ser elucidado na citação:

Em oposição às soluções dadas pela ciência e sua metodologia científica, a fenomenologia existencial busca as soluções na descrição da experiência imediata. Vai à realidade vivida e busca a descrição cuidadosa da estrutura básica da experiência imediata. (...) A presença no mundo externo torna-se evidente através da análise fenomenológica da experiência imediata do sujeito. Isso quer dizer que através do fenômeno que se revela à consciência é possivel saber-se que o mundo está aí e que se doa ao Ser. Onde quer que o Ser esteja presente, na sua realidade vivida, haverá mundo, porque a própria existência humana é estar-nomundo. (Martins eBicudo, 1983, p. $38{ }^{14}$.

Para Heidegger ${ }^{12}$, "ser-no-mundo" refere-se à maneira pela qual o homem encontra-se com suas coisas e com as pessoas, preocupa-se com elas, num mundo que lhe é familiar, remetendo também ao modo como o Ser-no-mundo se aproxima das pessoas ou coisas e/ou se afasta delas. Dessa forma, a fenomenologia se preocupa com o aspecto social do Ser, passando a pensar em como ele vive o seu Ser-com-osoutros, como ele se relaciona, atua, sente e vive com seus semelhantes.

Diante de tal referencial, a pessoa que tem uma doença grave é um ser que tem uma parte de si afetada pela enfermidade, se apresentando como um "sendo-doente" e que, segundo Boemer ${ }^{15,16}$ é uma pessoa que tem seu mundo influenciado por esta vivência, que compromete suas possibilidades de vir-a-ser, trazendo a perspectiva do não ser que passa a se revelar com a consciência de que todo ser humano é um serpara-a-morte. 
Heidegger ${ }^{11}$ aponta o ser-com ou o sendo-com como um constitutivo do existir humano, do ser-aí. Ou seja, faz parte da natureza do homem a busca por contato, envolvimento com outros homens, outras existências. Com significa para ele junto, algo ou alguém na presença do outro. Sem essa palavra, não seria possível o relacionar-se, o atuar, o sentir, o pensar... Sem esta característica, a vida humana não teria sentido, já que para todas as ações estamos nos relacionando com algo ou alguém, por exemplo: lidar com algo, trabalhar com um material, brincar com alguém, falar comigo.

Nessa perspectiva, o profissional de saúde tem o seu ser-aí envolvido com o ser-que-está-doente, e a partir do momento que assume o cuidado do paciente em estado grave, passa a ser-com-o-outro-que-estámorrendo e esta relação sempre afeta, de alguma maneira, a sua existência.

Ainda segundo a ontologia heideggeriana:

Para os filósofos da existência, a morte é uma dimensão do completamento do ser-aí. $O$ Dasein, ou Ser-aí, chega à compreensão de sua totalidade e da significabilidade de si-mesmo que é inseparável da integridade, quando o Ser-aí se defronta com a possibilidade de não ser-mais-aí. Enquanto o Dasein não houver chegado ao seu próprio fim, ele permanece incompleto, ele não chegou a completar sua inteireza, sua totalidade. O Dasein tem acesso ao significado do Ser - e este é um ponto muito importante - porque somente o seu ser é finito. O Ser autêntico é, portanto, um ser-para-a-morte, um Sein-zum-Tote, uma das mais freqüentes citações de Heidegger, porém menos compreendida no pensamento moderno. (Heidegger, 2001) ${ }^{12}$.

A nossa experiência com as situações de morte e morrer advém da morte do outro, que nos remete à percepção de que também somos seres para a morte e que, em algum momento de nossa existência, passaremos pelo processo do morrer.

As intervenções de cuidado para com o paciente se apresentarão permeadas pela nossa postura frente ao morrer, como o ser-cuidador percebe o serque-precisa-ser-cuidado. Esta percepção percorre um caminho que pode ser linear e que, ao seu final, se encontra a morte ou ainda pode ser vida que a qualquer instante pode se deparar com sua finitude.

A partir da primeira maneira de se perceber a morte, ela é vista como uma intrusa na existência da pessoa e também como uma ameaça à onipotência do profissional de saúde que é quem, supostamente, deveria impedir este processo, apresentando a cura para o sofrimento do enfermo.

Assim sendo, podemos perceber situações onde, pela angústia do cuidador diante da possibilidade de morte do outro, alguns tipos de inter-relações se estabelecem na tentativa de negar essa possibilidade existencial. Situações como tratar o paciente como objeto, sem poder de reflexão ou decisão sobre a melhor forma de intervenção terapêutica, quando os profissionais se apegam excessivamente a protocolos de atuação relativos ao quadro clínico apresentado. Ou ainda situações onde há a crença de que o paciente não pode conhecer a gravidade de sua doença, de modo a ser protegido da ameaçadora notícia de que sua morte pode estar próxima.

É importante perceber que, à medida que, há uma certa conspiração, chamada por Kübler-Ross ${ }^{4}$ de "conspiração do silêncio", do profissional de saúde, paciente e a família, há a ilusão de que a doença grave pode ser facilmente contornável frente aos tratamentos propostos e que se trata apenas de uma situação comum, cotidiana. Entretanto o paciente, na maioria das vezes, percebe que algo não está indo bem e que seu quadro assusta os profissionais por ele responsáveis, podendo angustiar-se ainda mais, sem ter conhecimento da sua real situação e, o mais agravante, sem a possibilidade de escolha sobre como deseja passar seus últimos momentos de vida, refletindo sobre sua existência ou até tendo a oportunidade de reparar situações mal resolvidas e valorizar os relacionamentos que fazem parte de seu mundo.

As atitudes de negação por parte da equipe ou profissional de saúde podem ser compreendidas como uma necessidade mais relacionada às suas angústias pessoais de convívio com o morrer do que uma real necessidade para o melhor cuidado para com o paciente. Observamos situações nas quais o profissional nem ao menos buscou conhecer o paciente, seus anseios e projetos de vida e já concluiu que seria melhor que ele ignorasse e não soubesse da gravidade do quadro clínico, simulando uma situação de controle da situação. De acordo com Boemer ${ }^{16}$, em casos como o relatado acima, o principal prejudicado com essa conspiração é o próprio paciente com o sentimento de solidão e insegurança sobre sua própria vida.

Ainda é importante ressaltar que, segundo essa perspectiva filosófica da existência, o homem pode 
ser-com de maneira autêntica ou inautêntica. Autêntica de forma a propiciar um verdadeiro envolvimento entre o ser-no-mundo e seu objeto de atenção; já a maneira inautêntica de ser-com revela pouco envolvimento, como se houvesse um não reconhecimento das significações e da dimensão existencial da pessoa ou do objeto com o qual se relaciona.

Atento para o fato de que a autenticidade não aponta somente para experiências positivas e prazerosas, mas pode se remeter a dificuldades de aceitação do processo de morte e morrer, experiências negativas no cuidar do paciente nestas situações, superproteção, infantilização, desde que essas posturas e atitudes estejam acontecendo de forma envolvente e significativa para os profissionais. Ainda para Heidegger ${ }^{11}$, a existência humana é permeada por estados de autenticidade e inautenticidade que se alternam de modo que não é possível ao homem viver de maneira exclusivamente autêntica sua relação com o outro ou com algo, já que haverá momentos nos quais o referido objeto ou pessoa se tornará foco principal de sua existência e outros em que a atenção se voltará para outras esferas da existência.

Percebemos, em Steiner ${ }^{13}$, que a ontologia heideggeriana salienta a importância do cuidado enquanto "zelo", "preocupação", "sorge*" que possibilitaria a existência autêntica do ser humano, já que comprometida com seu ser-no-mundo. Entretanto, tal cuidado, estaria mais ligado às possibilidades mais próximas do ser humano em realizar coisas e ocupar-se de seu cotidiano, preocupar-se com os seus pertences e atividades.

Uma segunda forma de cuidado, de acordo com Heidegger ${ }^{11}$, se refere à solicitude que seria 0 relacionar-se com alguém, com um outro, de maneira envolvente e significativamente com ele, tendo como pressupostos a consideração e a paciência para com o existir do outro. A solicitude ainda se expressaria de duas maneiras: aquela que é caracterizada por um precipitar-se por sobre o outro, fazer tudo por ele, mimá-lo, manipulá-lo ainda que de forma sutil, e aquela que possibilita ao outro assumir seus próprios caminhos, ainda que com o amparo desse alguém que lhe é solícito.

Embora segundo o próprio autor seja impossível manter apenas relações de autenticidade nas situações de cuidado, é preciso que se busque a relação mais próxima possível com o paciente de quem se cuida de modo que ele possa ser percebido em sua dimensão existencial. Um cuidado em que o profissional se precipita sobre a pessoa que é cuidada, acreditando que está fazendo o melhor, pode trazer inúmeros prejuízos para a pessoa em tratamento, já que não vai haver uma co-existência entre o ser-cuidador e ser-cuidado, mas sim uma relação desprovida de significado real a ser acrescentado para ambas as partes envolvidas no ato de cuidar.

A partir das reflexões levantadas neste texto podemos dizer que a morte, apesar de ser uma parte da existência humana, traz consigo uma grande carga de angústias e temores para quem dela se aproxima e também para os profissionais de saúde que têm como responsabilidade prestar assistência aos pacientes gravemente enfermos. Assim, apenas pela da compreensão dessa possibilidade existencial do "não-ser" é que os médicos, enfermeiros, fisioterapeutas, psicólogos, entre tantos outros profissionais que trabalham com o paciente fora de possibilidades terapêuticas ou em estado grave poderão experienciar o cuidado autêntico com este ser-que-adoece, podendo se comprometer com uma assistência que não vise única e exclusivamente a cura, mas que favoreça o cuidado do paciente como um ser pleno de humanidade, com necessidades afetivas, sociais e com o direito de viver seu morrer com dignidade e respeito. Nesse sentido, a filosofia de cuidados paliativos pode se apresentar como um caminho para melhor assistir a pessoa em seu morrendo, pois segundo essa proposta o cuidar é sempre possível ainda que a cura não faça parte de seu horizonte de possibilidades.

*Vocábulo no idioma alemão 
Souza LGA, Boemer MR. The care in death situations: some reflections. Medicina (Ribeirão Preto) 2005; 38 (1): $49-54$.

Abstract: The perceptions about death and die have changed trough history, at first it was a pacific and wished experience but became a full of angst possibility, a situation that have to be avoid desperately. At this context, the health professionals have a great responsibility in promoting discussions and reflections about this question, trying to offer an authentic care, engaged whit the human being in his plenitude. This article has the purpose of discussing, based on Heidegger phenomenology, the death theme as a part of human existence, considering the necessity to understand the care practices and the ways of human relationships looking for enabling health workers to share with patients this existential moment that must to be lived with dignity.

Keywords: Death. Health Professionals. Care Relationships.

\section{REFERÊNCIAS BIBLIOGRÁFICAS}

1 - Souza LGA. Cuidando do filho com deficiência mental: desvelamentos de vivências de pais no seu ser-com-o-filho. [dissertação]. Ribeirão Preto:Escola de Enfermagem de Ribeirão Preto da Universidade de São Paulo;2003.

2 - Souza LGA. O cuidar de pessoas portadoras de deficiência mental: um estudo fenomenológico. [monografia, graduação Psicologia]. Ribeirão Preto: Faculdade de Filosofia Ciências e Letras de Ribeirão Preto da Universidade de São Paulo; 2000.

3 - Ariés P. A história da morte no Ocidente. Trad. PV Siqueira. Rio de Janeiro: Francisco Alves; 1977

4 - Kübler-Ross E. Sobre a morte e o morrer. 7ed. Trad. P Menezes. São Paulo: Martins Fontes; 1996.

5 - Kübler- Ross E. Perguntas e respostas sobre a morte e o morrer. Trad. WD Silva e TL Kipnie. São Paulo: Martins Fontes; 1979.

6 - Kastenbaum R, Aisemberg R. Psicologia da morte. Trad. AP Lessa. São Paulo: Pioneira /EDUSP; 1993.

7 - Martins JS. A morte e os mortos na sociedade brasileira. São Paulo: Hucitec; 1983.

8 - Ziegler J. Os vivos e a morte. Trad. A Weissemerg. Rio de Janeiro: Zahar; 1977.
9 - Pitta A. Hospital: dor e morte como ofício. 3ed. São Paulo:Hucitec; 1994.

10 - Ayres JRCM. Cuidado e reconstrução das práticas em saúde. Interface - Comunic Saúde Educ 2003/2004; 8(14):7392.

11 - Heidegger $M$. Todos nós... ninguém - um enfoque fenomenológico do social. Trad. DM Critelli e S Spanoides. São Paulo: Moraes; 1981.

12 - Heidegger M. Ser e Tempo. Trad. M S Cavalcante. Partes I e II. Petrópolis:Vozes;2001.

13 - Steiner G. As idéias de Heidegger. Trad. A Cabral. São Paulo: Cultrix; 1978.

14 - Martins J, Bicudo MAV. Estudos sobre existencialismo, fenomenologia e educação. São Paulo: Moraes; 1983.

15 - Boemer MR. A morte e o morrer. 3ed. Ribeirão Preto: Holos; 1998.

16 - Boemer MR. O fenômeno morte: o pensar, o conviver, o educar. [tese].Ribeirão Preto: Escola de Enfermagem de Ribeirão Preto da Universidade de São Paulo; 1989. 